\title{
Electrical power behavioral usage in public institutions and its intervention: a case of tanzania higher learning institutions
}

\author{
Simon Bazila ${ }^{1}$, Ellen Kalinga ${ }^{1}$, Kwame lbwe ${ }^{2}$ and Abdi T. Abdalla ${ }^{2^{*}}$ (I)
}

\author{
*Correspondence: \\ abdit@udsm.ac.tz \\ ${ }^{2}$ Department of Electronics \\ and Telecommunications \\ Engineering, College \\ of Information \\ and Communication \\ Technologies, University \\ of Dar es Salaam, Dar es \\ Salaam, Tanzania \\ Full list of author information \\ is available at the end of the \\ article
}

\begin{abstract}
Public institutions in developing countries, taking Tanzania as an example, are facing huge electricity consumption bills caused by inefficient utilization of electrical power. The causes of inefficient power usage can be due to the users' behavioral and inadequacy of technology deployment in electric controlling infrastructure. This study explores the users' behavior and the consequences of inefficient power utilization in Tanzania Higher Learning Institutions (HLIs). Around $85 \%$ of the sampled participants in the selected HLIs were least concerned with power saving strategies while using office facilities. The study reveals that inefficient energy consumption may result in high electrical power bills, unnecessary energy waste, psychological effects caused by inability to pay electrical bills and distress resulting from frequent power outages. Besides, the study proposes both behavioral- and technological-based interventions for electrical power saving in HLIs.
\end{abstract}

Keywords: Electrical power, Energy efficiency, Higher learning institutions, Technological intervention, User behavior

\section{Introduction}

Electricity is a vital resource toward sustainable development of any country but it still faces many growing challenges that relate to rising demand, inefficient catastrophe managament, inadequate generation and stability issues [1]. The need for electrical power is rising all around the world and it is expected that by 2040, energy demand will increase by $39 \%$ [2]. One of the most important components of a power system is overhead transmission lines. Due to the remote position of power stations from the load, these lines are the sources of electrical energy in power systems, from power generation to distribution or consumer levels [3]. Tanzania, as an example, by the year 2019, electricity covered only $39.46 \%$ of its total area of which $67.5 \%$ in urban and $32.5 \%$ in the villages [4]. According to [4], Tanzania is generating a total of 1,601.896 MW for institutions, colleges, schools, hospitals, industries and residences. The power generation capacity is not sufficient to meet demand with the newly developed policy of Tanzania for Industrialization. The studies further reveal that the little power generated is not efficiently utilized especially in public sectors, including Higher Learning Institutions (HLIs). HLIs

(C) The Author(s) 2022. Open Access This article is licensed under a Creative Commons Attribution 4.0 International License, which permits use, sharing, adaptation, distribution and reproduction in any medium or format, as long as you give appropriate credit to the original author(s) and the source, provide a link to the Creative Commons licence, and indicate if changes were made. The images or other third party material in this article are included in the article's Creative Commons licence, unless indicated otherwise in a credit line to the material. If material is not included in the article's Creative Commons licence and your intended use is not permitted by statutory regulation or exceeds the permitted use, you will need to obtain permission directly from the copyright holder. To view a copy of this licence, visit http:// creativecommons.org/licenses/by/4.0\%. 
are given higher privilege to access electricity though the rate of power wastage is relatively high and hence increasing running costs.

Tanzania is currently implementing a policy that supports industrialization where many projects require electricity such as Standard Gauge Railway and other modern industries, which have been the main agenda of the Nation [5]. To meet the demand, Tanzania is currently striving to implement the largest power plant in Rufiji River known as Julius Nyerere Hydropower project [6]. The project is expected to contribute 2115 Megawatt to the Nation Grid.

Inefficient use of electricity is a global challenge. For instance, the study conducted by [7] showed that $40 \%$ of the energy produced in the USA is used by public buildings and $\$ 2.8$ billion is wasted every year due to leaving ON electric appliances, including air-conditioning and lights, during night and weekends. The potential for energy efficiency and for reducing energy demand was up to $75 \%$ and $90 \%$ in the existing and new buildings, respectively. This is due to changes in design practices, technologies and behaviors [8].

In [9], the authors state that transforming today's energy systems in industrialized countries requires a substantial reduction in the total energy consumption at the individual level. To improve energy efficiency is sought to be the most cost-effective option for meeting growing energy demand in most countries [10]. If necessary, measures of both people's behavioral usage of electricity and technological means of controlling electricity will not be intervened, then a lot of electrical power will still be wasted.

In [11], the authors synthesized empirical evidence to identify what types of behavior change intervention are most successful for saving energy in the public workplace. The field of health-related behavior change interventions and adopted the Behavior Change Wheel (BCW) framework by [11]. The study found that interventions creating social and physical opportunities for employees to save energy are the most successful which constitute Enablement (including direct support and greater control to employees), Environmental Restructuring (particularly automated and retro-fitted technologies) and Modeling (various forms of social influence). The communal nature of most workplaces demands scrutiny to understand the effect of social influences.

\section{Related works}

The study by [12] investigated the effect of a large-scale behavioral intervention to conserve energy in the workplace involving the energy-saving competition among bank branches. More than 500 branches were involved for a period of one year. Using a difference-in-difference estimation, it was found that the competition significantly reduced monthly electricity consumption outside the work schedule by $7 \%$. However, the overall energy consumption did not change significantly. According to [12], this study had policy implications and they resulted in questioning the applicability of behavioral policies in the workplace or at least underscore the importance of considering the characteristics of the context in the policy's design. An intervention targeting the total energy consumption of a branch did not seem effective.

A work by [13] investigated the effect of human behavior and efforts to change the behavior on electricity consumption in high school settings. The research focused on awareness of energy use in public schools to decrease electrical energy consumption. The energy efficiency awareness campaign was found to have a positive impact on decreasing 
levels of electricity consumption. Unfortunately, these decreases lessened over time and hence awareness needs to be continuous. The key attributes of communication, motivation, and leadership were identified as necessary at the high school facilities level to ensure long-term success in decreased electrical consumption.

This work acknowledges the change of behavior approach as a solution to the electrical energy saving in HLIs. However, the approach needs a lot of effort including providing incentives through bonuses and gifts to employees in order to save energy. This paper examines the behavioral use of electrical power in Tanzania HLIs and proposes a different technology-based method of power saving. The paper encourages the HLI to act to control energy consumption using technological-based interventions including smart appliances or auto peak load management, in which case the energy saving will be more effective.

\section{Behavioral usage of electric power}

\section{Consumers' behavior on electric power usage}

Electricity is the major engine that drives the economy of any country. Consistent and reliable supply of electricity is vital for public and private institutions, and residences as most of the undelaying tasks are power dependents [14]. Reducing the amount of energy used and taking efficient measures can reduce energy consumption and save customers money. This behavioral change is more related to the amount paid against billing costs to private and public users [15]. Consumer behavior is an interdisciplinary research field that employs mainly psychological, sociological and economic theories to assess and predict consumer choices.

In [16], authors state that energy-saving behavior is often influenced by monetary incentive and shall not be generalized into an office building context whereby the users have no financial responsibility on its utility's expenses. According to the report presented by [17], if the occupants are directly involved in paying the energy bills, their approach in using energy shall be more radical compared to the ones who are not involved in paying the bills. Studies also found that barriers to energy behavioral change may be caused by employees not paying the bills, being unaware of the energy demands of the office, or not seeing any benefit for themselves directly in energy savings [18].

In the literature, social scientist devised different consumers' behavioral theories and models including theory of planned behavior and psychological determinants of proenvironmental behavior.

\section{(a) Theory of planned behavior}

Theory of Planned Behavior (TPB) consists of three psychological determinants, which are Attitude, Subjective Norm (SN) and Perceived Behavior Control (PBC). Attitude as the first predictor is defined as the beliefs, feelings and action tendencies of a person toward certain issues. It can be described as the subjective judgment of an individual to perform a certain behavior with either positive or negative benefits. Individual intention to perform certain behavior can be influenced by positive attitude [19].

Subjective norm as the second predictor is based on the social pressure from a specific reference group whereby an individual tries to comply. In [16], authors identified 
six indirect determinants influencing energy-saving behavior such as attitude, subjective norm, habit, perceived behavior control, energy knowledge and motivation. Social Norm is the relevant expectations of a community to which an individual seeks to comply. Personal Norm on the other hand can be explained by three fundamentals: when the individual is aware of the action necessary to solve the issues; when the individual recognizes the action is related to the issues; and when the individual recognizes their own ability to change the situation and condition. PBC as the final predictor refers to the individual's perception of the difficulty to perform certain behavior and their perceived control over the behavior [20].

\section{(b)Psychological determinants of pro-environmental behavior}

Psychological determinants can be explained as variables that may contribute to fostering individual intention toward energy-saving behavior. According to [21, 22], occupant's behavior change toward energy conservation can result in greater savings compared to the investment cost made for technological approaches. In the context of energy-saving behavior in institutions, psychological determinants include Attitude, subjective norm, PBC, and Personal Norm [23].

Energy efficiency through change of energy-related behavior represents promising energy savings. Building occupants' behavior has a great influence on final energy consumption as elaborated in [24]. According to [11], capability, opportunity, and motivation (COM-Behavior) interact to generate behavior that in turn influences these components as shown in Fig. 1. Capability refers to the individual's psychological and physical capacity to engage in the concerned activity which includes the necessary knowledge and skills. Motivation is related to brain processes that energize and direct behavior, not just goals and conscious decision-making. It includes habitual processes, emotional responding and analytical decision-making. Motivation is the cognitive processes that energize and direct behavior, not just goals and conscious decision-making but also automatic associations and priming. Opportunity, on the other hand, refers to the factors that lie outside the individual but make the behavior possible. The single-headed and double-headed arrows in Fig. 1 represent potential influence between components in the system [11].

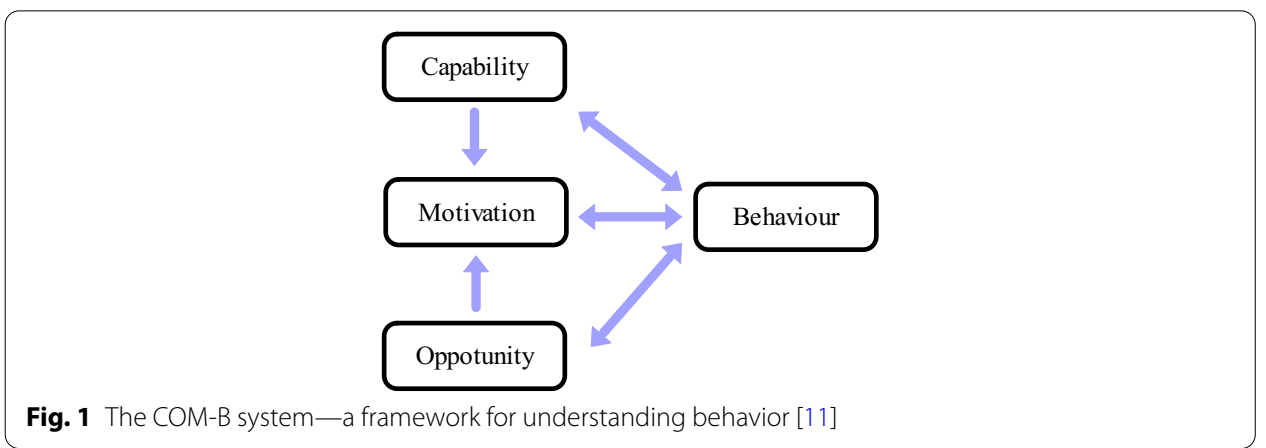




\section{Cognitive Internet of things for efficient energy consumption}

Currently, the Internet of Things (IoT) technology has attracted the attention of many researchers and is rapidly growing with the business environment. IoT connects physical things like vehicles, buildings, and various devices to the Internet using embedded intelligent sensors and microcontrollers [25, 26]. IoT can be considered as a global network which facilitates communication between human-to-human, human-to-things and things-to-things, by providing unique identity to each and every object.

IoT is the major contributor toward the advancement of smart grid beyond the monitoring and automation. In the field of smart grid, it performs the following tasks [27].

(i) In Automated Meter Infrastructure (AMI), IoT-enabled smart meters and communication systems enable advanced monitoring up to the consumer end.

(ii) In Supervisory Control and Data Acquisition (SCADA), IoT with Artificial Intelligence (AI) and Machine Learning (ML) allows several advanced functions like multisite integration, predictive maintenance, and fault prevention.

(iii) In Smart inverters, IoT enables solar- or battery-based inverters to manage power flows and respond to grid stability requirements in real time. Rooftop solar inverters when integrated with smart grid applications of the utility can extend their smart functions for multiple purposes.

(iv) It allows remote operation of energy consuming devices to respond to grid requirements and utility pricing signals.

IoT is all about identifying, sensing and communicating technologies with a vision of anytime, anywhere and any media but the communicated data are not foreseen and lack the major decision-making characteristic which is an elementary requirement of smart environment [28]. This requirement triggered the emergence of Cognitive IoT (CIoT) which provides greater improvements in performance and brings in intelligence among the devices in the network. Unlike IoTs, CIoTs interact with network devices with minimum human intervention as the latter integrate the human cognitive into the systems [29]. Figure 2 shows the CIoTs framework and how its four layers interact [29].

(i) Sensing control layer has a direct interface with the physical environment in which the receptors sense the environment by processing the incoming stimuli and feedback observations to the upper layer and the actuators act to control the perceptors.

(ii) Data-semantic-knowledge layer effectively analyzes the sensing data to form useful semantic and knowledge. In CIoT, semantic means deriving and adopting various technologies from the analyzed information.

(iii) Decision-making layer uses the semantic and knowledge extracted from the lower layer to reason, plan and select the most suitable action from multiple agents to support services for human/social networks and stimulate adaptation to the physical environment. To realize this task, machine learning and microcontrollers are used.

(iv) Service evaluation layer shares important interfaces with social networks in which, on-demand service is enabled to social networks and novel performance metrics are designed to evaluate the provisioned services and feedback the evaluation result to the cognitive process. 







\section{Methodology}

In this study, both qualitative and quantitative methods were adopted where a sample of 70 staff and students were involved where $29 \%$ were staff and $71 \%$ were students, randomly selected from Tanzania HLIs. Questionnaires and document analysis were used to gather information. The numeric data were analyzed using SPSS and excel, while the qualitative data were analyzed using content analysis. Some of the questions regarding electric power usage at homes and offices include how careful they are while using electrical power and to what extent each is involved in saving electric power usage. The questions intended to find out their experiences on how people handle electric power at homes and offices. Electrical bills and payments in one HLI were also collected as secondary data to see the trend of payment against electrical usage.

\section{Findings}

As shown in Fig. 3, the majority of participants confirmed that they are extremely cautious when using electricity in their homes, while $84 \%$ stated that they are not at all cautious when using electricity in public institutions. Only $15 \%$ were moderately cautious, and $1 \%$ were extremely cautious when using electricity.

The majority of participants are actively interested in reducing electrical power usage at home, but they are not formally involved in reducing electrical power usage at work because no one has been questioned if he or she has misbehaved on electrical power usage. When in office, all 70 participants use indoor lighting, computers/laptops, printers, projectors, fans, and air-conditioning.

The nature of HLIs comprises constituent colleges, schools, institutions, centers, student hostels, dispensary, lecture theaters, administrative blocks, Library and Widens houses. Thus, HLI consists of a large community which demands electric power for different uses. HLIs face a challenge of paying high power bills caused by genuine and nongenuine uses. Unfortunately, the bills are paid centrally and end users are unaware of the amount paid by the institution except for concerned administrators, thus resulting in energy waste and hence costs since users are not in position to differentiate the high consuming appliance with the least consuming [30, 31].

From one of the visited HLIs in Tanzania, it was found that out of 10 months billing data, the lowest total billing cost paid was TZS 159.5 million in May 2020 and the highest was TZS 252.7 million in January 2021 as summarized in Fig. 4.

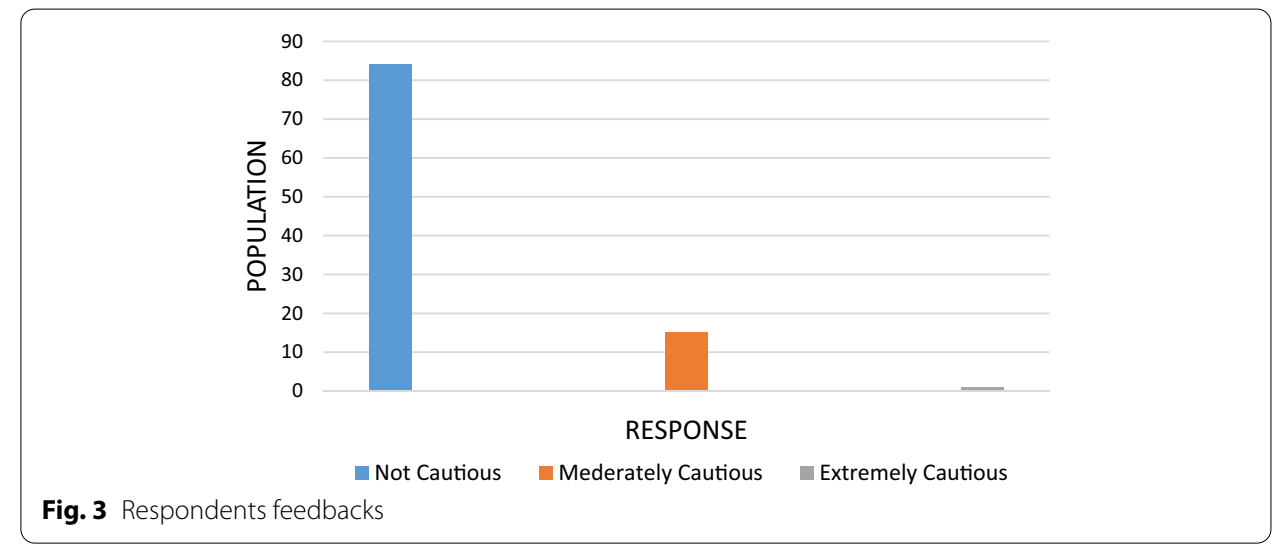




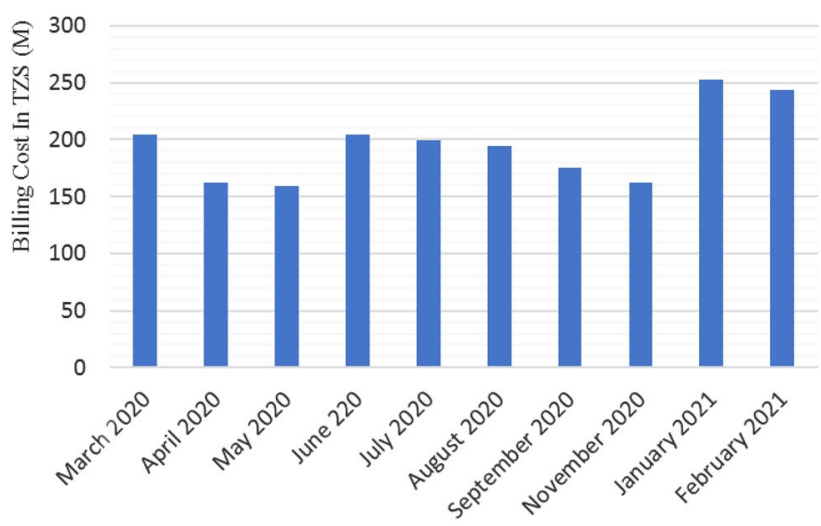

Month

Fig. 4 One year total electrical power billing paid for nine months

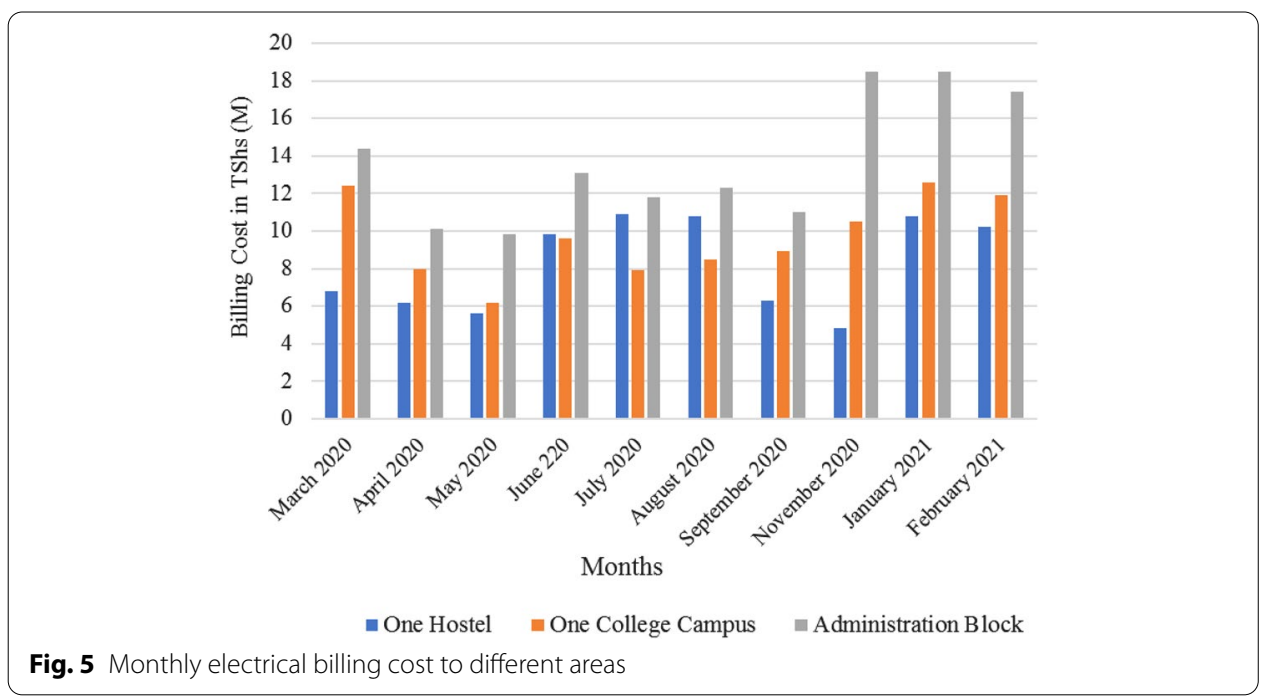

Comparing different blocks of the same HLI including students' hostel, college campus and administration block, it was found that the nature of electrical power used in hostels are more of lights, campus college is a mixture of lights, air conditions and laboratory equipment. From the data, the administration block contains a good number of air conditions as well as lights and registered the highest bill of TZS 18.5 Million in November 2020 and January 2021, while students' hostel registered the lowest. Figure 5 shows the total electric bills for the same three considered areas per month from March 2020 to February 2021, while Fig. 6 shows the cumulative total amount paid in those similar months.

From Fig. 6, a total one year paid bill for the administration block was around TZS $137 \mathrm{M}$, higher than TZS 96.9 $\mathrm{M}$ of the college campus TZS 82.5 M paid for one students' hostel. The high registered bill for administration block is possibly associated by the large number of electric appliances including ACs as summarized in Table 1. 


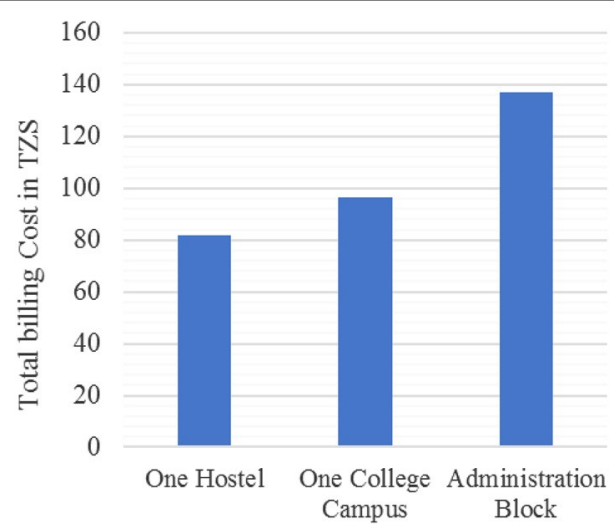

Fig. 6 Total electrical billing cost to different areas of CoICT of UDSM

Table 1 Power consumption for the most commonly used appliance in HLIs

\begin{tabular}{llc}
\hline No & Appliance category & $\begin{array}{c}\text { Power } \\
\text { consumption } \\
\text { (W) }\end{array}$ \\
\hline 1 & Projector & 282 \\
2 & Tube light 4 ft & 36 \\
3 & Laptop & 65 \\
4 & Fan & 120 \\
5 & Air condition (AC) & 1250 \\
6 & Printer & 50 \\
7 & Photocopier & 183 \\
8 & Fridge & 300 \\
9 & Television & 75 \\
10 & Microwave & 1800 \\
11 & Electric Kettle & 2000 \\
\hline
\end{tabular}

\section{Intervention to control and save electrical power}

\section{Behavioral change interventions}

Power improving efficiency can be improved through facilitating behavior change toward the use of electrical power to public institutions. The suggested behavioral change wheel $(\mathrm{BCW})$ model by [11] provides interventions to facilitate behavior change. Applying this intervention design, the task would be to consider what the behavioral target would be, and what components of the behavior system would need to be changed to achieve the goal. In the $\mathrm{BCW}$, the elements have been categorized as intervention functions and policy categories. In the context of electric power, behavioral use in HLIs intervention functions includes restrictions, education, persuasion, coercion, training, enablement and modeling while policy categories can include guidelines, regulation, service provision, legislation, communication/marketing and fiscal measures.

Though $\mathrm{BCW}$ was developed targeting to intervene and promote health activities, similar concepts can be adopted in electric power usage. In that regard, the following areas can be revisited: 
(i) Education: need to increase awareness on the importance of power saving which in turn will reduce electrical bills. Insisting on switching OFF office and laboratory electrical power to air conditions when leaving rooms and laboratories.

(ii) Persuasion: using communication to induce positive feelings or stimulate actions like using imagery to motivate physical activities. Communication can be through social media such as WhatsApp and Instagram groups.

(iii) Training: imparting skills on being responsible in using public facilities in the public areas

(iv) Modeling: providing and demonstrating real positive behavior in using public facilities, hereby referring to electrical power.

Relying on behavioral change may sometimes be a challenge due to the rational and selfish behaviors of some employees especially in the state of market failure [12]. Employees save energy only if they have been incentivized through bonuses and gifts, otherwise, the HLI has to act to control its employees' energy consumption using technological-based interventions including smart appliances or auto peak load management [32].

\section{Technological intervention measures}

Efficient power management needs the integration of Information and Communication Technology (ICT) on consumers' demand-side. This can be efficiently realized using smart meters and Cognitive IoT. Recent advances in smart meter technology allow a range of new functions such as remote meter reading, time-of-day tariffs and real-time data usage information which can be exploited in conjunction with smart sensors to enhance power usage efficiency [33]. A study by [34] incorporating smart meters can play a major role in behavior change since energy consumption notifications alert the consumers through their mobile phones and enhance reduction in bills.

\section{Cognitive loT}

For the public institution including HLIs, it is important to establish intelligent systems to automate the sensing of the load parameters and intelligently control the electric power usage as shown in Fig. 7. This can be accomplished using the CloTs-based system. A proposed CIoT system consists of a microcomputer called the Raspberry Pi 4 as the main controller, with trained Tanzania Meteorological Agency data (TMA) being used with the designing regression model for predicting a decision based on collected data from three sensors: temperature sensor, lights sensor, and motion detection for environmental data gathering in a room. Fans, air conditioners, and lights will be connected to a relay switch that is also connected to the grid and the Raspberry Pi 4 . The decision to turn on or off will be based on modal findings compared to sensor data. As shown in Fig. 7, a database will be utilized to store room consumption and then provide a report.

\section{Discussion}

Climate nature in Tanzania, specifically Dar es Salaam, has long hot and sunny seasons. Due to that, institutional offices, classrooms and laboratories are being facilitated with air-conditioning and electric fans. This also includes lighting and power points for other 


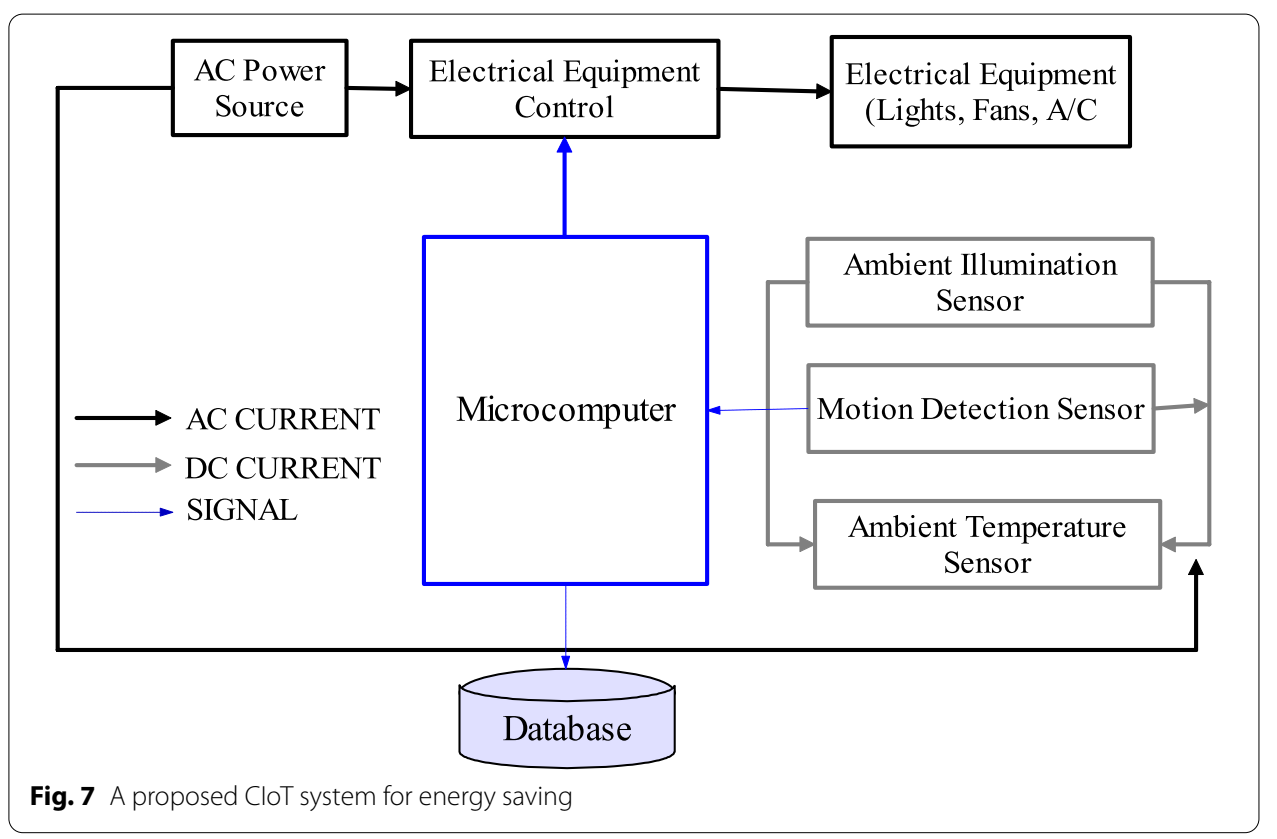

use like computers, printers and scanners. Electrical equipment connected to power points has no significant impact on electrical usage, since appliances connected to them automatically go to "hibernation/sleeping" mode when not used for long (not actively used), automatically conserving the electric power. Problems are with air conditions, lighting and electric fans where by, unless measures are being taken, they will remain to be the facilities to subject HLIs with very high electric billing. Behavioral usage of electricity in all units is a challenge as the majority are not careful. Lights are left $\mathrm{ON}$ in offices and classrooms whether it is sunny or cloudy, this is the same as security lights. Air conditions and lights are left $\mathrm{ON}$ even if nobody is in the offices during weekdays and sometimes on weekends. The usage is more based on the behavioral side, people are not concerned with the effect of not being responsible.

It is of no doubt that people are very cautious in using electrical power at home, some measures taken are to switch ON lights and other appliances only when there is a need. According to participants during data collection, people are not careful in using electrical power due to reasons that they are not responsible for paying bills and they do not know the huge amount paid and its consequences; they are not motivated or encouraged and they have not been provided with guidelines in using public resources. Actually, to a big extent, electrical power is being left ON during power cuts, where people (staff and student) leave switches for lights and air conditions ON incautiously that the power may return any time. Sometimes while attending other activities outside the office and expecting to immediately return back, it turns out that a staff member may not return back to office and a room is closed.

Intervention to make people change behavior toward using electrical power is one way, but its impact is not promising as people are forgetful. There is a need to intervening the matter technologically to control power. It is time for HLIs to save costs used to pay electric bills, as the saved amount may be used to solve many other issues in the institutions. 


\section{Conclusions}

This study investigated the repercussions of electrical power consumption patterns on both the institution and the utility business in Tanzania. Content analysis on behavior trend toward the use of electricity in offices shows that, $85 \%$ of respondents said they are not cautious when using electricity, $14 \%$ said they are cautious when using electricity, and only $1 \%$ said they are extremely cautious while using electricity. It can be determined that inefficient power use has disastrous consequences such as increased electricity bills (unneeded expenditures) that have costing implications, unnecessary power wastage, and excessive power generation machinery and creating insufficient power to customer in demand due to wastage of power. Based on the data from three buildings of one of the university campuses, administration block have more air conditions compared to students' hostel (mostly having lighting fittings) and college campus (having lights and few Air Conditions) has the highest electrical bills in all months from March 2020 to February 2021, however, the most was on November 2020 and January 2021 amounting to 19 million Tanzania Shillings. Accumulatively, the electrical billings for all 10 months were amounting to 137 million Tanzania Shillings for Administration block, 82 million Tanzania Shillings for student's hostel and 97 million Tanzania Shillings for one college campus.

Making people change their behavior toward the use of electrical power is of no doubt very important, however, the trend shows that this effort does not result in a promising impact, especially when they are not involved in paying bills and are not consistent. People are forgetful and need to be reminded frequently. Technological-based interventions are the best solutions in controlling electrical power, which many of the public organizations and institutions in developing countries, including Tanzania do not apply. There is a need for the concerned management to prioritize the matter and advantages of it will be: the saving of electrical energy, the cost reduction in electrical bills and the money saving from the reduced billing costs that can be used for other issues.

This study is looking forward to implementing a CIoT that operates autonomously on the process of energy conservation as a future development. There is a need to first create a framework and establish the controlling mechanisms, taking the advantage of the IoTs and machine learning technologies.

Abbreviations

ACs: Air conditions; Al: Artificial intelligence; AMI: Automated meter infrastructure; BCW: Behavioral change wheel; CloT: Cognitive Internet of things; EC: Energy conservation; HLIs: Higher learning institutions; ICT: Information and communication technologies; loTs: Internet of things; PBC: Perceived behavior control; SN: Subjective norm; SCADA: Supervisory control and data acquisition; TPB: Theory of planned behavior.

Authors' contributions

SB performed data collection and analysis. EK wrote the initial draft of the manuscript, KI reviewed the manuscripts and AA performed intensive review of the manuscript. All authors have read and approved the manuscript.

Funding

No funding received.

Availability of data and materials

All data generated or analyzed in this study are included in the manuscript.

\section{Declarations}




\begin{abstract}
Author details
${ }^{1}$ Department of Computer Science and Engineering, College of Information and Communication Technologies, University of Dar es Salaam, Dar es Salaam, Tanzania. ${ }^{2}$ Department of Electronics and Telecommunications Engineering, College of Information and Communication Technologies, University of Dar es Salaam, Dar es Salaam, Tanzania.
\end{abstract}

Received: 22 August 2021 Accepted: 10 February 2022

Published online: 02 March 2022

\title{
References
}

1. Makala B, Bakovic T (2020) Artificial intelligence in the power sector. Int. Financ. Corp: 1-8

2. Ansari MM, Guo C, Shaikh MS, Chopra N, Haq I, Shen L (2020) Planning for distribution system with grey wolf optimization method. J Electr Eng Technol 5:1485-1499

3. Shaikh MS, Hua C, Jatoi MA, Ansari MM, Qader AA (2021) Parameter Estimation of AC Transmission Line Considering Different Bundle Conductors Using Flux Linkage Technique. IEEE Canadian J Electr and Comp Eng 44(3): 313-320

4. Tanesco (2021) TANESCO - Distribution. http://www.tanesco.co.tz/index.php/about-us/functions/distribution: accessed Apr. 03, 2021.

5. Kweka J (2018) Monitoring Policies to Support Industrialisation in Tanzania: An Update and Policy Recommendations. Support. Econ. Transform.

6. World Wildlife Fund (2017) The true cost of power: the facts and risks of building stiegler's gorge hydropower dam in Selous game reserve. Tanzania 36:54

7. Cibinskiene A, Dumciuviene D, Andrijauskiene M (2020) Energy consumption in public buildings: the determinants of occupants' behavior. Energies 13(14):3586

8. Lucon O et al. (2014) AR5 Climate Change 2014: Mitigation of Climate Change. Working Group III contribution to the Fifth Assessment Report of the Intergovernmental Panel of Climate Change, pp. 671-738.

9. Burger $\mathrm{P}$ et al (2015) Advances in understanding energy consumption behavior and the governance of its change-outline of an integrated framework. Front Energy Res 3:1-19

10. UNEP DTU (2017) Overcoming barriers to investing in energy efficiency. United Nations New York and Geneva.

11. Staddon SC, Cycil C, Goulden M, Leygue C, Spence A (2016) Intervening to change behaviour and save energy in the workplace: a systematic review of available evidence. Energy Res Soc Sci 17:30-51

12. Fanghella V, D'Adda G, M. Tavoni M (2021) Behavioral intervention to conserve energy in the workplace. FAERE working paper: 2020.21.

13. Kemp-Hesterman A, Glick S, Cross JE (2004) Reducing electrical energy consumption through behaviour changes. J Facil Manag 12(1):4-17

14. Otegbulu AC (2011) A contingent valuation model for assessing electricity demand. J Financ Manag Prop Constr $16(2): 126-146$

15. Zhang H, Gladisch A, Pickavet M, Tao Z, Mohr W (2010) Energy efficiency in communications. IEEE Commun Mag 48(11):48-49

16. Mansor R, Sheau-Tingi L (2019) The psychological determinants of energy saving behavior. In:IOP Conf. Ser. Mater. Sci. Eng. 620(1): 012006.

17. Somuncu Y (2017) Influence of the users behaviour on the energy performance of the buildings. Monitoring plan and user behaviour recommendation for the NEED4B methodology.

18. Reeves A, Morton A, Bull R (2017) Design for Behaviour Change for Energy End-Users.

19. Greaves M, Zibarras LD, Stride L (2013) Using the theory of planned behavior to explore environmental behavioral intentions in the workplace. J Environ Psychol 34:109-120

20. Lülfs R, Hahn R (2014) Sustainable behavior in the business sphere: a comprehensive overview of the explanatory power of psychological models organ. Environ 27(1):43-64

21. Yeboah FK, Kaplowitz MD (2016) Explaining energy conservation and environmental citizenship behaviors using the value-belief-norm framework. Hum Ecol Rev 22(2):137-159

22. Khashe S, Heydarian A, Becerik-Gerber B, Wood W (2016) Exploring the effectiveness of social messages on promoting energy conservation behavior in buildings. Build Environ 102(3):83-94

23. Lokhorst AM, Staats H, Van Iterson J (2015) Energy saving in office buildings: Are feedback and commitmentmaking useful instruments to trigger change? Hum Ecol 43(5):759-768

24. Karatasou S, Laskari M, Santamouris M (2013) Models of behavior change and residential energy use: a review of research directions and findings for behavior-based energy efficiency. Adv Build Energy Res 8(2):137-147

25. Aydin I, Othman NA (2017) A new loT combined face detection of people by using computer vision for security application. In: 2017 International Artificial Intelligence and Data Processing Symposium.

26. Bhargavi B (2016) An introduction to cognitive internet of things : new perspective of loT. Int J Eng Res \& Tech 4(29):1-4

27. Chuah J (2014) The internet of things: an overview and new perspectives in systems design. In: 2014 International Symposium on Integrated Circuits (ISIC): 216-219.

28. Atzori L, lera A, Morabito G (2010) The internet of things: a survey. Comput Netw 54(15):2787-2805

29. Wu Q et al (2014) Cognitive internet of things: a new paradigm beyond connection. IEEE Internet Things $1(2): 129-143$

30. Graml T, Loock C, Baeriswyl M, Staake M (2011) Improving residential energy consumption at large using persuasive systems.

31. Sulaiman E et al. (2007) A study on electric energy usage at the residential area. 1st Eng. Conf. Energy Environ. pp. 27-28. 
32. Karjalainen S (2016) Should we design buildings that are less sensitive to occupant behaviour? A simulation study of effects of behaviour and design on office energy consumption. Energy Effic 9(6):1257-1270

33. Castri R, De Luca V, Lobsiger-Kägi E, Moser C, Carabias V (2014) Favouring behavioural change of households' energy consumption through social media and cooperative play. In: Behave Energy Conference.

34. Kambule N, Yessoufou K, Nwulu N (2018) Energy for Sustainable development review a review and identi fi cation of persistent and emerging prepaid electricity meter trends. Energy Sustain Dev 43:173-185

\section{Publisher's note}

Springer Nature remains neutral with regard to jurisdictional claims in published maps and institutional affiliations.

Submit your manuscript to a SpringerOpen ${ }^{\circ}$ journal and benefit from:

- Convenient online submission

- Rigorous peer review

- Open access: articles freely available online

- High visibility within the field

- Retaining the copyright to your article

Submit your next manuscript at $\boldsymbol{\Delta}$ springeropen.com 